\title{
Jean Potocki, Manuscrit trouvé à Saragosse (version de 1804), Manuscrit trouvé à Saragosse (version de 1810)
}

\section{Luc Fraisse}

\section{(2) OpenEdition}

10 Journals

\section{Édition électronique}

URL : http://journals.openedition.org/studifrancesi/8288

DOI : 10.4000/studifrancesi.8288

ISSN : 2427-5856

Éditeur

Rosenberg \& Sellier

\section{Édition imprimée}

Date de publication : 1 mai 2009

Pagination : 186-187

ISSN : 0039-2944

\section{Référence électronique}

Luc Fraisse, "Jean Potocki, Manuscrit trouvé à Saragosse (version de 1804), Manuscrit trouvé à

Saragosse (version de 1810)», Studi Francesi [En ligne], 157 (LIII | I) | 2009, mis en ligne le 30 novembre 2015, consulté le 09 janvier 2021. URL : http://journals.openedition.org/studifrancesi/8288; DOI : https://doi.org/10.4000/studifrancesi.8288

Ce document a été généré automatiquement le 9 janvier 2021.

\section{(c) $($ ) $\odot$}

Studi Francesi è distribuita con Licenza Creative Commons Attribuzione - Non commerciale - Non opere derivate 4.0 Internazionale. 


\title{
Jean Potocki, Manuscrit trouvé à Saragosse (version de 1804), Manuscrit trouvé à Saragosse (version de 1810)
}

\author{
Luc Fraisse
}

\section{RÉFÉRENCE}

JEAN POTOCKI, Manuscrit trouvé à Saragosse (version de 1804), Manuscrit trouvé à Saragosse (version de 1810), éd. François ROSSET et Dominique TRIAIRE, Flammarion, «GF», 2008, 2 voll., pp. 770 et 862 .

1 «L'énigme du Manuscrit enfin résolue», annonce le bandeau entourant les deux volumes. De quelle énigme s'agit-il? La découverte a récemment donné lieu à une édition scientifique chez Peeters, en 2006: au sein des Euvres de Jean Potocki (1761-1815) en cinq tomes et six volumes, les tomes IV-1 et IV-2 présentaient les deux versions du roman ici réédité dans une collection de poche, accessible, mais conservant tout l'appareil critique de l'édition savante, avec des introductions renouvelées. Car le romancier, grand seigneur polonais de langue française, est un grand voyageur ethnographe, historien curieux de l'origine des civilisations et promoteur des chronologies comparées, et a connu deux périodes politiques parallèles, l'une à la grande Diète de Varsovie, l'autre au service de la Russie, à la source de tout un ensemble d'écrits politiques (il a fondé et dirigé deux journaux). Le roman, Manuscrit trouvé à Saragosse, écrit en plus de vingt ans, est resté son compagnon de route, repris entre ou pendant ses périodes de voyage et d'action politique. Il met en scène deux mois d'initiation à la vie, reçue par le héros, Alphonse van Worden, dans la chaîne montagneuse de la Sierra Morena, par la seule entremise de récits qui lui sont faits par la troupe de Bohémiens avec laquelle il se trouve cheminer, des récits à tiroirs pouvant atteindre un enchevêtrement complexe, et entretenant entre eux des ressemblances et des différences énigmatiques. 
2 L'énigme cependant ne touche pas ici au contenu du récit, mais à l'histoire du texte, celle d'un roman commencé dans les années 1790 et terminé en 1815, au moment où son auteur se suicide dans la propriété de Podolie en Ukraine où il s'est retiré. Rappelons les étapes de ce parcours, qui forme à lui seul un roman. 1813 et 1814: Potocki, craignant que les frontières d'Ukraine se trouvent bloquées, a envoyé un manuscrit de son roman à un éditeur parisien, Gide, lequel y découpe arbitrairement deux récits sans l'aveu de l'auteur, Avadoro, histoire espagnole et Dix Journées de la vie d'Alphonse van-Worden; Potocki a-t-il même eu connaissance de ces parutions qui dépècent son œuvre et en voilent durablement la réalité et la structure, on ne le sait. 1847: plus de trente ans après la mort de l'auteur, Edmund Chojecki fait paraître à Leipzig une traduction polonaise de Manuscrit trouvé à Saragosse, qui devient un monument patrimonial à part entière; dans quelles circonstances ce personnage, qui a séjourné à Paris, a-t-il entrepris ce grand travail de traduction, et sur quels manuscrits a-t-il pu se fonder (les papiers de Potocki avaient été divisés en cinq lots, correspondant à ses enfants), il est difficile, pour l'instant encore, de l'identifier; mais cette traduction donne durablement l'idée à la postérité d'un roman «complet» et unifié. 1958 et 1967: Roger Caillois publie chez Gallimard, sous le titre Manuscrit trouvé à Saragosse, un tiers du roman comprenant surtout le début, ce qui provoque la redécouverte en France de cette œuvre, mais oriente sa lecture vers le fantastique (dont la portée était réévaluée dans la suite et fin du roman): Tzvetan Todorov se sert de Manuscrit dans sa célèbre définition du fantastique. Nouvelle période de relatif oubli. 1989: René Radrizzani publie chez José Corti la première version dite «intégrale» française du roman, en soixante-six journées; la structure et la portée générales du roman sont ainsi données à comprendre pour la première fois au public français; le but est de proposer l'équivalent de la traduction de Chojecki, c'est-à-dire de restaurer l'œuvre idéale, en refondant des versions disparates de façon à obtenir le récit continu le plus complet possible; quand manquent les manuscrits originaux pour certaines parties, il faut en fait retraduire la traduction polonaise (via l'allemand); ce projet connaît sa réalisation la plus achevée dans l'édition du Livre de Poche en 1995.

3 C'est ici qu'entrent en scène nos deux éditeurs, François Rosset et Dominique Triaire. Ils ont retrouvé à travers l'Europe des manuscrits autographes pour toutes les parties du roman (il n'est donc plus nécessaire de s'en remettre parfois à la traduction polonaise). Et ils ont découvert que Potocki a mis successivement en chantier trois versions différentes de son roman: ces trois versions, on peut les dater par le filigrane du papier notamment (Potocki utilisait ses feuilles généralement dans l'année suivant leur achat), ce qui n'avait pas été fait jusqu'ici; elles ne constituent pas exactement les brouillons successifs de l'œuvre, car chacune obéit à une conception différente de la narration, tournée dans une direction qui la rend autonome. De l'une à l'autre, les journées du récit n'ont pas le même numéro, ne suivent pas du tout le même ordre: un personnage comme le géomètre Velasquez, apparaissant assez tôt au départ, fera une entrée au contraire tardive dans la dernière version, laquelle en outre ne comportera plus du tout l'histoire du Juif errant. Chojecki, dans son travail de traduction, a-t-il pleinement aperçu le problème? Toujours est-il qu'il a proposé, selon l'idéal du temps, une version entièrement unifiée, rafistolée chaque fois que les manuscrits des différents états ne se rejoignent pas, inventant même une conclusion à l'histoire du Juif errant, dans un récit en soixante-six journées (le roman véritable de Potocki en comporte soixante et une). 
Qu'enseigne donc la vérité des archives? Il existe une première mouture du roman, dite version de 1794: de cette version, on ne possède que les journées 19 à 39 (le début n'ayant pas été retrouvé), à cause de quoi elle n'est pas publiée, mais peut être lue sur le CD-Rom fourni avec l'édition du t. IV aux éditions Peeters. Une deuxième version, de 1804, donnée ici, s'arrête à la $45^{\mathrm{e}}$ journée. Elle comporte l'histoire du Juif errant (sans conclusion). C'est la version la plus complexe, la plus ramifiée (le roman à tiroirs parvient jusqu'à cinq relais emboîtés de narration). Arrivé à ce stade, Potocki change d'avis, des passages entiers sont barrés dans les manuscrits. Il choisit de redonner à son roman une marche beaucoup plus rectiligne (les emboîtements se simplifient), d'en resserrer aussi l'action dans l'espace et dans le temps (à cause de quoi entre autres disparaît le Juif errant), d'en modifier enfin la portée (de façon complexe, car si beaucoup de passages sont discrètement réécrits pour voiler l'érotisme ou les provocations antireligieuses, le développement des systèmes philosophiques exposés par les personnages accentue au besoin le scandale). Il en résulte la version de 1810, terminée par son auteur dans une "Conclusion de tout l'ouvrage» à la $61^{\mathrm{e}}$ journée (nous la lisons pour la première fois dans le texte français d'origine) qui dévoile l'action concertée et complexe de la secte des Gomelez sur Alphonse.

5 Sauf à retrouver des manuscrits intermédiaires qui proposeraient, de la main de Potocki, une harmonisation des deux versions (c'est difficile à concevoir), sauf si le traducteur Chojecki avait disposé d'indications de ce genre pour élaborer sa version unifiée, il faut donc à présent lire ce grand roman en deux versions parallèles, version de 1804 et version de 1810 . Nous y aide cette édition comprenant, dans chaque tome, une longue présentation de l'œuvre, une genèse de la version correspondante, un texte annoté (l'annotation est évidemment reproduite d'un tome à l'autre, quand les éléments du récit sont restés les mêmes), une chronologie détaillée (les éditeurs ont fait paraître en 2004, chez Flammarion, une biographie de l'auteur, biographie qui éclaire les abandons et reprises successifs du roman) et une bibliographie de et sur Potocki. Fondée sur des documents fiables rendus accessibles à un large public, la postérité de Manuscrit trouvé à Saragosse peut, enfin, maintenant commencer. 